\title{
Estimated glomerular filtration rate in apparently healthy term neonates in Nigeria
}

\author{
Akpoembele Deborah Madise-Wobo', Elizabeth Aruma Disu',2, Olusegun Henry Gbelee ',2, Adaobi Solarin', \\ Barakat Adeola Animasahun 1,2 \\ 'Lagos State University Teaching Hospital and 'Lagos State College of Medicine, Lagos, Nigeria.
}

\section{ABSTRACT}

Background: Glomerular filtration rate (GFR) is the best measure of renal function. However, the ideal exogenous markers are not routinely used to estimate GFR in clinical settings. Outside Africa, GFR estimates for neonates have been calculated from formulae using creatinine as well as cystatin C. There is a paucity of data on estimated GFR in neonates in Africa. This study was conducted to estimate GFR in healthy term African neonates using cystatin C-based equations.

Methods: One hundred and thirteen apparently healthy term babies with normal Apgar scores were recruited at birth. Cystatin $\mathrm{C}$ was measured in cord blood at birth and in venous samples from neonates on the third day of life. GFR was estimated using the Filler and Lepage as well as the Zappitelli et al. cystatin C-based equations. These estimates were compared with a reference GFR estimate of $41 \pm 15 \mathrm{~mL} / \mathrm{min} / 1.73 \mathrm{~m}^{2}$.

Results: The median (interquartile range) estimated GFR values based on cord blood and day 3 venous samples using the Filler and Lepage equation were 44.67 (36.35-72.44) and 51.29 (38.90-72.44) mL/min/l .73 $\mathrm{m}^{2}$, respectively. When the Zappitelli equation was applied, the estimates were 38.18 (31.84-61.34) and $43.82(33.75-61.34) \mathrm{mL} /$ $\mathrm{min} / 1.73 \mathrm{~m}^{2}$, respectively. The GFR estimates derived from both equations did not differ in respect of the gestational age, sex and postnatal ages of the babies.

Conclusions: GFR estimates using the Zappitelli equation had values that were closely related to reference GFR measures for neonates whereas the GFR estimates using the Filler and Lepage equation had higher values.

Keywords: GFR, neonates, cystatin C, cord blood.

\section{INTRODUCTION}

Glomerular filtration rate (GFR) is defined as the volume of plasma that is completely cleared of a particular substance by the kidneys in a unit of time [I]. GFR is widely accepted as the best measure of renal function [2-4]. In order to detect abnormal renal function, it is important to establish reference values for GFR using reliable methods of evaluation.

The most precise method for measuring GFR is to use exogenous markers like inulin. Measurement of inulin clearance involves the intravenous injection of a priming dose followed by constant infusion and meticulous urine sampling. Other exogenous markers such as iohexol, sodium iothalamate, technetium-diethylenetriaminepentaacetic acid (Tc-DTPA), and chromiume-thylenediaminetetraacetic acid ( $\mathrm{Cr}$ - EDTA) have also been used. Although the use of these exogenous markers is the gold standard, the need for frequent blood sampling, careful urine collection and constant infusions limits their use in the clinical setting. Because of these limitations, researchers have sought simpler methods of assessing GFR. Serum creatinine has been used to estimate GFR for decades. Plasma or serum creatinine as a marker of renal

Received 30 May 20 I7; accepted 25 May 20I 8; published 30 June 2018. 
function is not ideal as it is dependent on muscle mass, gender, age and tubular maturity $[5,6]$, it crosses the placenta and thus reflects maternal values in the first days of life $[6,7]$ and it is insensitive to small changes in GFR [6]. Finally, the Jaffe method, which is the most commonly used method for measuring creatinine, is prone to interference in conditions such as hyperbilirubinaemia, haemolysis and ketosis $[1,6]$. This leads to falsely high serum creatinine measurements and underestimation of GFR.

Serum cystatin $C$ has been proposed as a more reliable marker in children and adults and offers significant advantages over serum creatinine. Cystatin $C$ may also be used to replace creatinine when assessing renal function in neonates. Cystatin $C$ is a cysteine proteinase inhibitor, which is involved in the intracellular catabolism of proteins [6]. It is expressed in all nucleated cells and produced at a constant rate [8]. Many studies have validated the use of cystatin $C$ as a marker of renal function in paediatric populations $[1,9,10]$. Cystatin $C$ appears to be a more specific and sensitive marker of GFR in neonates and older children compared to creatinine $[1,10,1|-| 4]$.

There are few studies that have evaluated renal function in neonates using ideal exogenous markers [15]. In studies conducted outside of Africa, GFR estimates have been reported using the clearance of creatinine $[16,17]$ and cystatin $C[15,18]$. To the best of our knowledge, no GFR estimates have been documented in African neonates. The objectives of the present study were to estimate GFR in apparently healthy neonates in Nigeria at birth and on the third day of life, using cystatin C-based equations, and to compare the estimated GFR with previously published reference values $[15,16]$. This study therefore provides useful data on the normal values for renal function in healthy African neonates. The results reported here focus on GFR and represent part of a larger study; details of the methods and results of cystatin $C$ levels have been published previously [22].

\section{METHODS}

This was a prospective study of apparently healthy full-term neonates delivered at the Obstetrics and Gynaecology unit of a Mother and Child Health Facility in Lagos State from October to December 2014. The hospital is the Obstetrics and Gynaecology annex of the Lagos State University Teaching Hospital (LASUTH), a tertiary institution in South West Nigeria.

We recruited I I 3 full-term, apparently healthy babies after normal pregnancy, labour and delivery. These were babies with a 5-minute Apgar score of more than 7, and who had a birth weight that was appropriate for gestational age. Babies who experienced conditions likely to affect renal function were excluded. These included babies of mothers with hypertension, babies with gross congenital anomalies and those who developed fever or evidence of systemic illness by the third day of life.

Blood samples were obtained from the umbilical cord at birth and venous samples on the third day of life. Serum cystatin $C$ was measured on the samples using Human Cystatin C ELISA kits (BioVendor-Laboratorni a.s., Czech Republic) [19]. The calibration range of the assay was 200$10,000 \mathrm{ng} / \mathrm{mL}$, with a limit of detection of $0.25 \mathrm{ng} / \mathrm{mL}$. Its intra-assay coefficient of variation was $2.5 \%$ and the interassay coefficient of variation was $6.9 \%$.

Estimated GFR (eGFR), expressed in $\mathrm{mL} / \mathrm{min} / 1.73 \mathrm{~m}^{2}$, was calculated using two prediction equations, with cystatin $\mathrm{C}$ concentration in $\mathrm{mg} / \mathrm{L}$ :

Filler and Lepage equation [20]: $\log (e G F R)=1.962+$ [1.123 $\times \log ($ l/cystatin C)]

Zappitelli et al. equation [2 I]: eGFR $=75.94 \times$ cystatin $c^{-1.17}$.

Data analysis was preformed using Microsoft Excel 2013 and the Statistical Package for Social Sciences (SPSS) version 20.0. Mean and standard deviation were calculated for variables that were normally distributed; median and interquartile range were used for variables that were not normally distributed. Comparisons between groups were made using Student's t-test, and the Wilcoxon signed-rank, Mann-Whitney $U$ and Kruskal-Wallis tests were used for non-parametric data. P-values of less than 0.05 were considered statistically significant.

Approval for the study was granted by the Health Research and Ethics Committee of LASUTH. Informed consent was obtained from the parents of the neonates. The parents of babies with congenital anomalies or evidence of renal impairment were counselled and referred for appropriate follow-up.

\section{RESULTS}

A total of 144 babies were recruited, but 24 did not return for evaluation on the third day of life, or were ill on that day, and so were excluded from the study. Another seven had haemolysed samples and were also excluded. The remaining neonates were 45 males and 68 females (ratio $1: 1.5$ ). Their baseline characteristics are summarised in Table I. Most of the babies were delivered at 37-38 weeks. The birth weight ranged from $2.5-4.5 \mathrm{~kg}$, with a mean weight of $3.4 \pm 0.5 \mathrm{~kg}$.

The mean cystatin $C$ values at birth and on day 3 , as reported previously, were $1.67 \pm 0.52 \mathrm{mg} / \mathrm{L}$ and $1.62 \pm$ $0.52 \mathrm{mg} / \mathrm{L}$, respectively, with medians of 1.8 and $1.6 \mathrm{mg} / \mathrm{L}$ [22]. There were no differences based on the time of sampling or the sex of the neonates (Figure I). 


\begin{tabular}{|c|c|c|}
\hline Variable & Frequency & Percentage \\
\hline \multicolumn{3}{|l|}{ Sex } \\
\hline Male & 45 & 40.7 \\
\hline Female & 68 & 59.3 \\
\hline \multicolumn{3}{|c|}{ Gestational age at birth (weeks) } \\
\hline $37-38$ & 57 & 50.4 \\
\hline $39-40$ & 42 & 37.2 \\
\hline$\geq 41$ & 14 & 12.4 \\
\hline \multicolumn{3}{|l|}{ Weight at birth (g) } \\
\hline 2500-2999 & 28 & 24.8 \\
\hline $3000-3499$ & 46 & 40.7 \\
\hline$\geq 3500$ & 39 & 34.5 \\
\hline \multicolumn{3}{|l|}{ Mode of delivery } \\
\hline SVD* & 30 & 26.5 \\
\hline Caesarean section & 83 & 73.5 \\
\hline \multicolumn{3}{|c|}{ Maternal age (years) } \\
\hline$\leq 18$ & 0 & 0 \\
\hline $19-30$ & 49 & 45 \\
\hline $31-40$ & 58 & 53.2 \\
\hline$\geq 41$ & 2 & 1.8 \\
\hline
\end{tabular}

"SVD, spontaneous vaginal delivery.

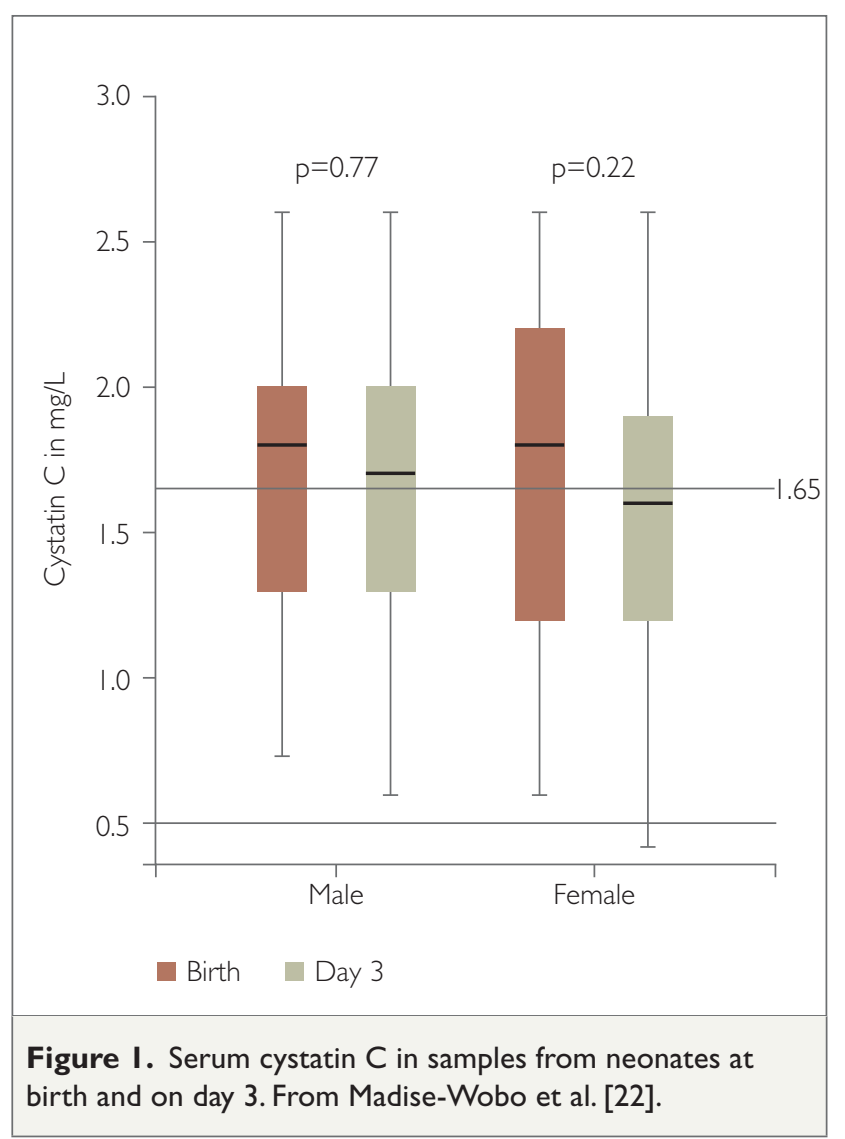

Table 2. Estimated GFR* (median and interquartile range) using the Filler and Lepage equation [20].

\begin{tabular}{|lcccc|}
\hline Gender & $\mathrm{n}$ & Birth & Day 3 & $\mathrm{P}$ \\
\hline Male & 45 & $\begin{array}{c}44.67 \\
(34.68-76.82)\end{array}$ & $\begin{array}{c}53.70 \\
(38.90-72.44)\end{array}$ & 0.34 \\
& & 44.47 & 49.58 & \\
Female & 68 & $(38.02-70.85)$ & $(41.69-67.23)$ & 0.98 \\
& & 44.67 & 51.29 & \\
Total & 113 & $(36.35-72.44)$ & $(38.90-72.44)$ & 0.53 \\
& & 0.69 & 0.57 & \\
\hline
\end{tabular}

"GFR in $\mathrm{mL} / \mathrm{min} / 1.73 \mathrm{~m}^{2}$.

Table 3. Distribution of eGFR values using the Filler and Lepage [20] equation at birth and on day 3 .

\begin{tabular}{|lcc|}
\hline $\begin{array}{l}\text { GFR } \\
\left(\mathrm{mL} / \mathrm{min} / 1.73 \mathrm{~m}^{2}\right)\end{array}$ & $\begin{array}{c}\text { Birth } \\
{[\mathrm{n}=113(\%)]}\end{array}$ & $\begin{array}{c}\text { Day 3 } \\
{[\mathrm{n}=113(\%)]}\end{array}$ \\
\hline$\leq 25.0$ & $0(0.0)$ & $0(0.0)$ \\
$25.1-40.0$ & $41(36.3)$ & $30(26.5)$ \\
$40.1-55.0$ & $25(22.1)$ & $33(29.2)$ \\
$55.1-70.0$ & $18(15.9)$ & $20(17.7)$ \\
$\geq 70.1$ & $29(25.7)$ & $30(26.5)$ \\
\hline
\end{tabular}

Table 4. Effect of gestational age on eGFR values using the Filler and Lepage equation at birth and on day 3.

\begin{tabular}{|llllc|}
\hline Age (weeks) & $\mathrm{n}$ & Birth & Day 3 & $\mathrm{P}$ \\
\hline 37 & 18 & 55.07 & 58.94 & 0.796 \\
38 & 39 & 47.35 & 50.50 & 0.766 \\
39 & 16 & 62.78 & 58.42 & 0.887 \\
40 & 26 & 47.35 & 59.60 & 0.192 \\
41 & 14 & 44.56 & 46.6 & 0.638 \\
$\mathrm{P}$ & & 0.425 & 0.454 & \\
\hline
\end{tabular}

Table 2 shows the eGFR values calculated using the Filler and Lepage equation [20]. The median eGFR was 44.67 and $51.29 \mathrm{~mL} / \mathrm{min} / 1.73 \mathrm{~m}^{2}$ at birth and on day 3 , respectively. There was no difference between males and females or between the samples taken at birth and on day 3 .

The eGFR values using the Filler and Lepage equation were grouped from the lowest to the highest (Table 3). There were no values less than $25 \mathrm{~mL} / \mathrm{min} / \mathrm{l} .73 \mathrm{~m}^{2}$. The distribution of eGFR values was similar for both birth and day 3 samples $(p=0.403)$.

There was no significant difference in the eGFR values across the different gestational ages for both cord blood and day 3 venous samples (Table 4). 
The eGFR values calculated using the Zappitelli equation [2I] are shown in Table 5. Once again, there was no difference between males and females or between the samples taken at birth and on day 3 .

The distribution of eGFR values using the Zappitelli equation (Table 6) was similar for samples taken at birth and on day 3. The largest number of samples was in the group with eGFR $25.1-40 \mathrm{~mL} / \mathrm{min} / 1.73 \mathrm{~m}^{2}$.

As noted with eGFR values calculated using the Filler and Lepage equation, there was no difference by gestational age at birth or by day 3 .

The eGFR values obtained using the Filler and Lepage equation were significantly higher than those using the Zappitelli equation (Table $7, \mathrm{p}<0.00 \mathrm{I}$ ).

Figure 2 illustrates the distribution of eGFR values derived from both equations. The plot depicts medians and interquartile ranges, and outliers; the reference GFR is represented by the horizontal line across the graph. The spread of the estimates from the Filler and Lepage equation was greater and the estimates from the Zappitelli equation

Table 5. Estimated GFR values using the Zappitelli equation.

\begin{tabular}{|lccc|}
\hline \multicolumn{4}{c|}{$\begin{array}{c}\text { eGFR median and interquartile range } \\
\text { (25th and 75th percentiles) }\end{array}$} \\
Gender & Birth & Day 3 & P \\
\hline Male & $38.18(30.18-64.63)$ & $45.83(33.75-61.34)$ & 0.39 \\
Female & $38.18(33.75-59.98)$ & $42.32(35.84-56.63)$ & 0.98 \\
Total & $38.18(31.84-61.34)$ & $43.82(33.75-61.34)$ & 0.60 \\
P & 0.93 & 0.34 & \\
\hline
\end{tabular}

Table 6. Distribution of eGFR values using the Zappitelli equation at birth and on day 3 .

\begin{tabular}{|lccc|}
\hline $\begin{array}{l}\text { GFR } \\
\left(\mathrm{mL} / \mathrm{min} / 1.73 \mathrm{~m}^{2}\right)\end{array}$ & $\begin{array}{c}\text { Birth } \\
{[\mathrm{n}(\%)]}\end{array}$ & $\begin{array}{c}\text { Day 3 } \\
{[\mathrm{n}(\%)]}\end{array}$ & $\mathrm{P}$ \\
\hline$\leq 25.0$ & $5(4.4)$ & $4(3.5)$ & 0.807 \\
$25.1-40.0$ & $54(47.8)$ & $47(41.6)$ & \\
$40.1-55.0$ & $19(16.8)$ & $24(21.2)$ & \\
$55.1-70.0$ & $18(16.0)$ & $22(19.5)$ & \\
$\geq 70.1$ & $17(15.0)$ & $16(14.2)$ & \\
\hline
\end{tabular}

Table 7. Comparison of eGFR values using the Filler and Lepage, and Zappitelli equations.

\begin{tabular}{|cccc|}
\hline & Filler and Lepage & Zappitelli & $P$ \\
\hline$\leq 25.0$ & $44.67(36.35-72.44)$ & $38.18(31.84-61.34)$ & 0.002 \\
$\geq 70.1$ & $51.29(38.90-72.44)$ & $43.82(33.75-61.34)$ & 0.003 \\
\hline
\end{tabular}

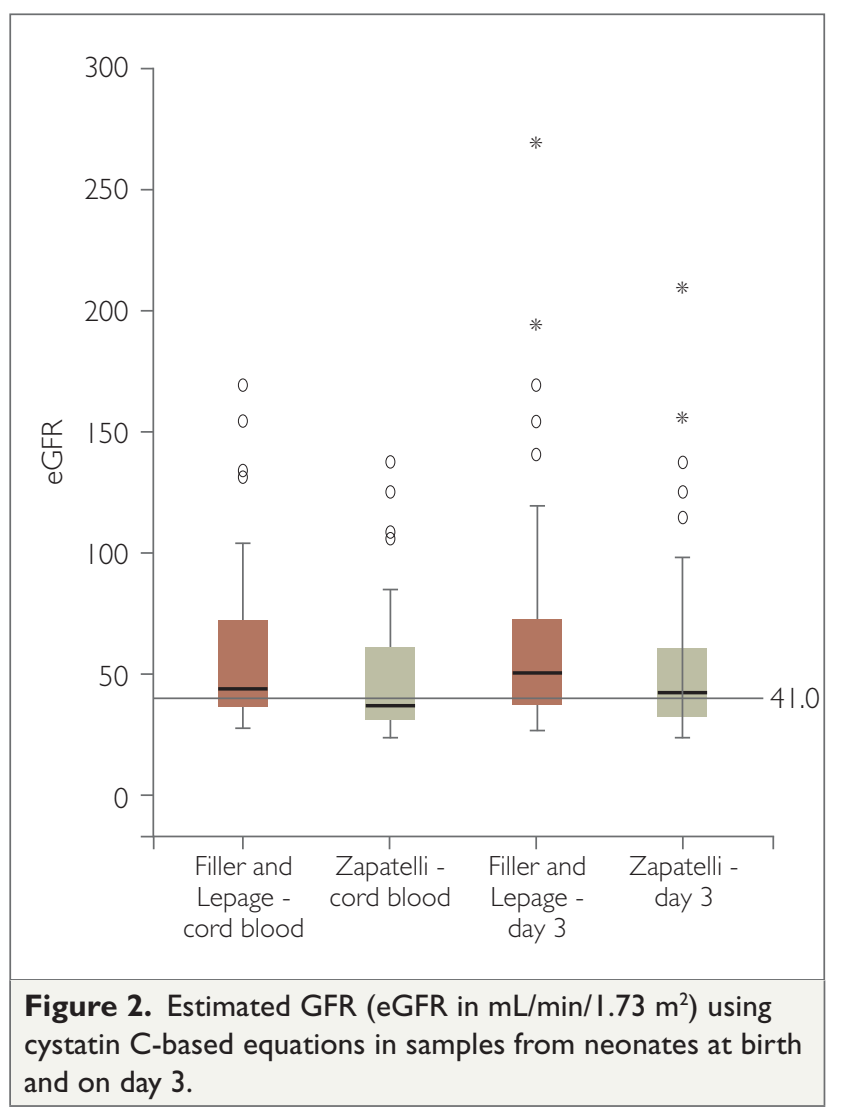

were more closely related to the reference value for both birth (cord blood) and day 3 samples.

\section{DISCUSSION}

We found that eGFR values calculated using the Filler and Lepage equation were higher than the reference values obtained from creatinine clearance in previous studies $[17,23]$. The eGFR values were also higher than those reported by Treiber et al. using a cystatin C-based equation formulated for neonates [15]. One reason for these differences may be that the Filler and Lepage equation overestimates GFR in children $[13,15,24,25]$. Since the development of the cystatin $C$ equation by Filler and Lepage, some researchers have noted that the equation overestimates GFR especially in the low GFR ranges $[15,26]$, whereas others reported that the equation correctly estimates GFR in children [2I].

GFR was also estimated using the Zappitelli equation [2I] because it has been proven to be more reliable when applied to older children and neonates [15,|8,26,27]. eGFR derived from the Zappitelli equation in our study was comparable with the measured reference range from creatinine clearance $[17,23]$ and the eGFR from the recently published cystatin $C$ equation derived for neonates [15]. Other researchers have also estimated GFR in neonates using the Zappitelli equation in neonates and reported that the eGFR from that equation was comparable with reference values measured by creatinine clearance $[15,18,27]$. 
In the present study, eGFR values calculated using the Filler and Lepage equation were significantly higher than those from the Zappitelli equation. This finding has also been documented in the study by Treiber et al. [15]. Given that the GFR estimates from the Zappitelli equation were more closely related to the reference GFR from the literature, the estimates from that equation may be used as reference values when investigating neonates at risk of renal injury in the first few days of life.

We observed that eGFR was independent of the gestational age, postnatal age and sex of the babies. This was not surprising, given that, in utero, GFR plateaus after the 36th week of gestation until birth. Thereafter, GFR correlates with postnatal age $[6,23]$. Previous reports have shown that there is no significant difference in the values in the first three days of life $[15,28]$. The implication is that separate reference values need not be generated for sex, gestational age of term babies and postnatal age in the first three days of life.

Some limitations were encountered: first, the inability to determine GFR using a gold standard method, which would have been compared with the estimates calculated from the cystatin $C$ equations. Second, the study included only term babies sampled at birth and on the third day of life. Third, the study would have added more value if preterm babies had been included and if all babies were also sampled at one month of age. The cost of the assays restricted the scope of the study.

\section{CONCLUSIONS}

GFR calculated using the Filler and Lepage equation yielded higher values than the estimates derived from the Zappitelli equation, which were comparable with GFR estimated using creatinine clearance in neonates.

\section{REFERENCES}

I. Laterza OF, Price CP, Scott MG. Cystatin C: An improved estimator of glomerular filtration rate? Clin Chem. 2002; 48(5):699-707.

2. Levey AS, Coresh J, Bolton K, Culleton B, Harvey KS, Ikizler TA, et al. $\mathrm{K} / \mathrm{DOQ}$ I clinical practice guidelines for chronic kidney disease: Evaluation, classification, and stratification. Am J Kidney Dis. 2002; 39 (2, suppl I): SI-266.

3. Salgado JV, Neves FA, Bastos MG, França AK, Brito DJ, Santos EM, et al. Monitoring renal function: Measured and estimated glomerular filtration rates - A review. Braz J Med Biol Res. 2010; 43(6):528-536.

4. Lamb EJ, Stevens EP, Deeks JJ. What is the best glomerular filtration marker to identify people with chronic kidney disease most likely to have poor outcomes? BMJ. 2015; 350:g7667.

5. Abiodun MT, Iduoriyekemwen NJ, Abiodun PO. Cystatin C-based evaluation of kidney function of HIV-infected children in Benin City, Southern Nigeria. Int J Nephrol. 2012; 2012:861296.

6. Otukesh H, Hoseini R, Rahimzadeh N, Hosseini S. Glomerular function in neonates. Iran J Kidney Dis. 20I2; 6(3): I66-I72.

7. Filler G, Priem F, Lepage N, Sinha P, Vollmer I, Clark H, et al. ß-trace protein, cystatin C, B2-microglobulin, and creatinine compared for detecting impaired glomerular filtration rates in children. Clin Chem.
8. Abrahamson M, Olafsson I, Palsdottir A, Ulvsback M, Lundwall A, Jensson $\mathrm{O}$, et al. Structure and expression of the human Cystatin C gene. Biochem J. 1990; 268(2):287-294.

9. Zaffanello M, Franchini M, Fanos V. Is serum cystatin-C a suitable marker of renal function in children? Ann Clin Lab Sci. 2007; 37(3):233-240.

10. Stevens LA, Schmid CH, Greene T, Li L, Beck GJ, Joffe MM, et al. Factors other than glomerular filtration rate affect serum cystatin C levels. Kidney Int. 2009; 75(6):652-660.

I I. Cordeiro VCF, Pinheiro DS, Silva GB, Lima SW, Mota RM, Libono $A B$ et al. Comparative study of $C y s t a t i n ~ C$ and serum creatinine in the estimation of glomerular filtration rate in children. Clin Chem Acta. 2008; 39I (I-2):46-50.

12. Parvex P, Combescure C, Rodriguez M, Girardin E. Is Cystatin C a promising marker of renal function, at birth, in neonates prenatally diagnosed with congenital kidney anomalies? Nephrol Dial Transplant. 20 I2; 27(9):3477-3482.

13. Bacchetta J, Cochat P, Rognant N, Ranchin B, Hadj-Aissa A, Dubourg $\mathrm{L}$. Which creatinine and cystatin $C$ equations can be reliably used in children? Clin J Am Soc Nephrol. 201 I; 6(3):552-560.

14. Asiloglu N, Acikgov Y, Paksu M, Gungaydin M. Is serum Cystatin C a better marker than serum creatinine for monitoring renal function in paediatrc intensive care unit? J Trop Paediatr. 20I2; 58(6):429-434.

15. Treiber M, Pečovnik Balon B, Gorenjak M. A new serum cystatin C formula for estimating glomerular filtration rate in newborns. Pediatr Nephrol. 20I5; 30(8) I297-I305.

16. Schwartz G], Feld L, Langford DJ. A simple estimation of glomerular filtration rate in full term infants during the first year of life. J Pediatr. 1984; 104(6):849-854

17. Brion LP, Fleischman AR, McCarton C, Schwartz GJ. A simple estimate of glomerular filtration rate in low birth weight infants during the first year of life: noninvasive assessment of body composition and growth. J Pediatr. 1986; 109(4):698-707.

18. Abitbol CL, Seeherunvong W, Galarza MG, Katsoufis C, Francoeur D, Defreitas $M$, et al. Neonatal kidney size and function in preterm infants: What is a true estimate of glomerular filtration rate? J Pediatr. 20।4; | 64(5): | 026-1031.

19. Biovendor datasheet. Available from http.//www.biovendor.com/ product/immunoassays/cystatin-c-human-elisa.

20. Filler G, Lepage N. Should the Schwartz formula for estimation of GFR be replaced by cystatin C formula? Pediatr Nephrol. 2003; 18(10):981-985.

21. Zappitelli M, Parvex P, Joseph L, Paradis G, Grey V, Lau S, et al. Derivation and validation of cystatin C-based prediction equations for GFR in children. Am J Kidney Dis. 2006; 48(2):22I-230.

22. Madise-Wobo AD, Gbelee OH, Solarin A, Animasahun BA and Olisamedua OF. Serum cystatin c levels in healthy Nigerian neonates: is there a need for normative values in Nigerian babies? Saudi J Kidney Dis Transpl. 20 I7; 28(6): 1247-1255.

23. Su SW, Stonestreet BS. Core concepts: neonatal glomerular filtration rate. Neoreviews. 20 I0; I I | 2):e7|4-2।.

24. Tidman M, Sjöström P, Jones I. A comparison of GFR estimating formulae based upon s-cystatin $C$ and s-creatinine and a combination of the two. Nephrol Dial Transplant. 2008; 23(I):I54-160.

25. Bouvet $Y$, Bouissou F, Coulais $Y$, Séronie-Vivien $S$, Tafani $M$, Decramer $S$, et al. GFR is better estimated by considering both serum cystatin $C$ and creatinine levels. Pediatr Nephrol. 2006; 21 (9): 1299-1306.

26. Nehus EJ, Laskin BL, Kathman TI, Blissler Jj. Performance of cystatin C-based equations in a pediatric cohort at high risk of kidney injury. Pediatr Nephrol. 20 I3; 28:453-46I.

27. Andersen TB, Eskild-Jensen A, Frøkiær J, Brøchner-Mortensen J. Measuring glomerular filtration rate in children; can cystatin $\mathrm{C}$ replace established methods? A review. Pediatr Nephrol. 2009; 24(5):929-941.

28. Aperia A, Broberger O, Elinder G, Herin P, Zetterstroum R. Postnatal development of renal function in pre-term and full-term infants. Acta Pædiatrica. 1981; 70(2): 183-187. 